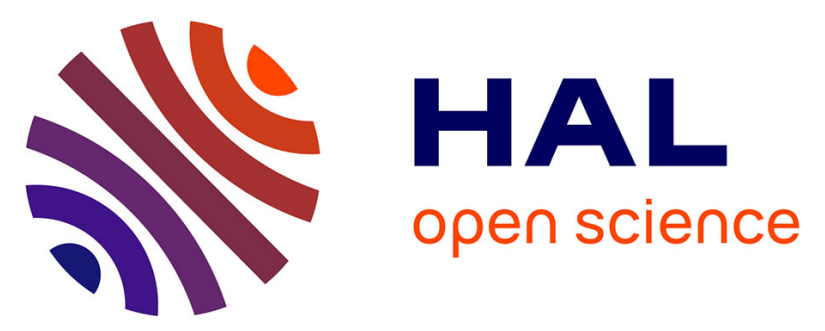

\title{
Stage II crack propagation direction determination under fretting fatigue loading: A new approach in accordance with experimental observations
}

Marie-Christine Baietto, Valérie Lamacq

\section{- To cite this version:}

Marie-Christine Baietto, Valérie Lamacq. Stage II crack propagation direction determination under fretting fatigue loading: A new approach in accordance with experimental observations. The 2nd International Symposium on Fretting Fatigue: Current Technology and Practices, Aug 1998, Salt Lake City, United States. pp.436-450. hal-01951929

\section{HAL Id: hal-01951929 \\ https://hal.science/hal-01951929}

Submitted on 13 Jul 2021

HAL is a multi-disciplinary open access archive for the deposit and dissemination of scientific research documents, whether they are published or not. The documents may come from teaching and research institutions in France or abroad, or from public or private research centers.
L'archive ouverte pluridisciplinaire HAL, est destinée au dépôt et à la diffusion de documents scientifiques de niveau recherche, publiés ou non, émanant des établissements d'enseignement et de recherche français ou étrangers, des laboratoires publics ou privés.

\section{(c)(1)}

Distributed under a Creative Commons Attribution| 4.0 International License 


\title{
Stage II Crack Propagation Direction Determination Under Fretting Fatigue Loading: A New Approach in Accordance with Experimental Observations
}

Marie-Christine Dubourg ${ }^{1}$ and Valérie Lamacq ${ }^{1}$

\begin{abstract}
Cracking is a dangerous degradation mode under fretting loading and the understanding of crack initiation and propagation is thus a necessity. A double experimental and theoretical approach has been undertaken to deal with crack initiation during Stage I [1,2], Stage I/Stage II transition and Stage II propagation. The work presented here is related to the latter point and aims at determining the direction and the propagation mode of cracks. A new approach is proposed here to account for nonproportional mixed mode conditions such as those encountered under fretting conditions at crack tips. Propagation directions during Stage II are derived from $\Delta \sigma_{\theta \theta}{ }^{*}$ max , the maximum effective amplitude of the tangential stress perpendicular to the crack trajectory. They correlate well with experimental data. The stress field analysis shows that the trajectory of cracks borders the tensile-compressive and the tensile zones existing around the crack tip over a loading cycle.
\end{abstract}

KEYWORDS: fretting, crack growth direction, non-proportional loading, contact, friction

\section{Introduction}

The two main degradation responses under fretting that are very often in the literature related to fretting wear and fretting fatigue are particle detachment and cracking whereas both can coexist in the same contact [3]. The first main degradation has been related to a fretting regime during fretting tests through the fretting map concept proposed by

${ }^{1}$ Research Scientist and Doctor, respectively, Laboratoire de Mécanique des Contacts, UMR-CNRS 5514, INSA, 20, Av A. Einstein, 69621 Villeurbanne Cédex, France. 
Vincent et al. [4]. Hence, the Running Conditions Fretting maps (RCFM) and the Material Response Fretting Maps (MRFM) (Figure 1) describe, respectively, the local fretting regime and the corresponding contact kinematics conditions (sticking, partial slip, gross slip) and the main fretting damage (non-degradation, cracking, and particle detachment) for normal load-displacement pairings. Cracking induced by fretting is a dangerous degradation mechanism and has been related, thanks to these maps, to partial slip conditions that occur under both the Mixed Fretting Regime and the Partial Slip Regime.

Experimental and theoretical work has been undertaken to improve our knowledge of crack initiation and propagation under fretting conditions. First, tests were conducted on 7075 aluminum alloys under Partial Slip and Mixed Fretting Regimes to obtain experimental data on crack behavior. Second, issues such as the location of crack initiation, initial crack growth direction during a macroscopic "Stage I", the conditions governing crack branching (Stage I/Stage II transition), crack growth direction during propagation (macroscopic "Stage $\Pi$ ") were theoretically addressed. It is shown that a new approach based on the continuum stress field analysis and on the Linear Elastic Fracture Mechanics is able to predict correctly the crack behavior and allows us to identify the respective influences of the contact and the external loading on crack behavior.

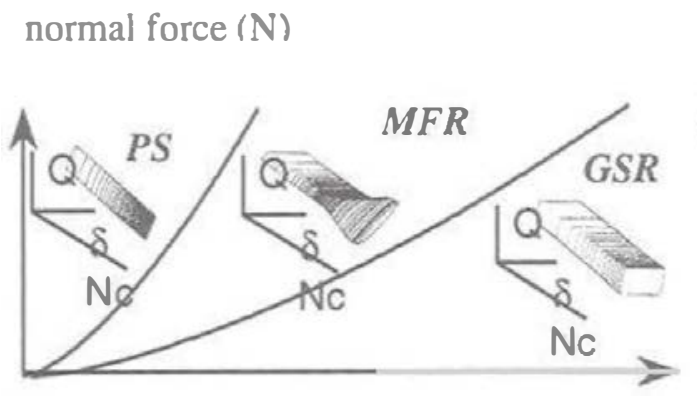

displacement amplitude ( $\mu \mathrm{m})$ normal force $(\mathrm{N})$

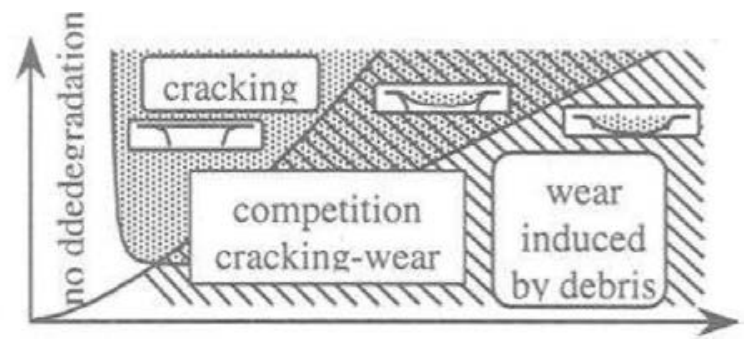

displacement amplitude

Figure 1 - Running Condition Fretting Map (RCFM) and Material Response Fretting Map (MRFM) (PS: Partial Slip characterized by quasi-closed $Q-\delta$ loops), MFR: Mixed Fretting Regime characterized by quasi-closed, parallelepipedic and elliptic $Q$ - $\delta$ loops, GSR: Gross Slip Regime characterized by parallelepipedic $Q-\delta$ loops) [5].

\section{Experiments and Observations}

A new device called a Pre-stressed Fretting Wear (FWPSS) [0] rig has been developed to study crack initiation and propagation under fretting conditions. The displacement amplitude being a governing parameter in crack initiation is here controlled. Whereas it is not possible during fretting fatigue testing as the displacement varies according to the elongation of the test specimen which itself varies with the 
applied oscillatory fatigue stress in the specimen. It is very difficult in that case to correlate the crack geometry with the local contact conditions. The FWPSS test has the great advantage that all mechanical parameters can be controlled during loading. The external load is fixed during testing and the relative displacement between contacting pads is imposed as in the case of the fretting wear (FW) (Figure 2). Further the RCFMs being almost the same under FW and FWPSS [7], it is possible to study separately the effects of fretting and external loading on cracking behavior.

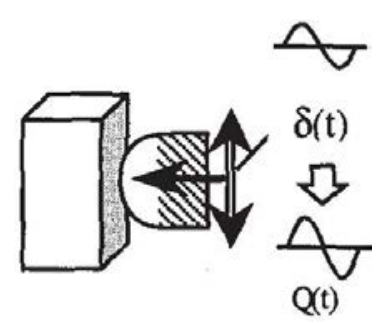

a)

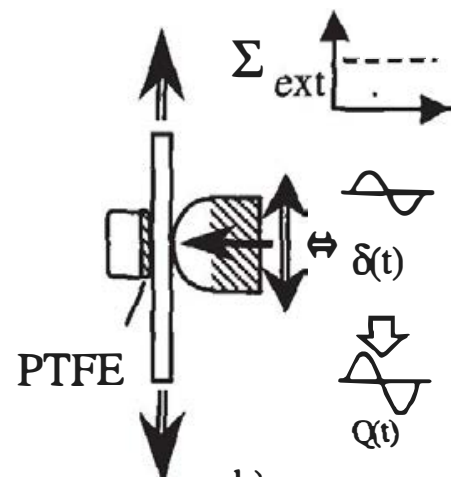

b)

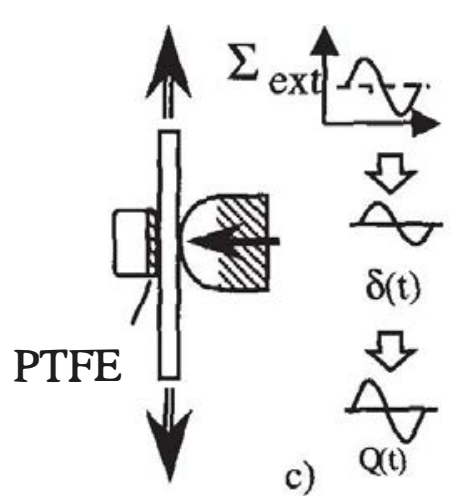

c)

Figure 2 - a) Fretting Wear (FW), b) Fretting Wear on pre-stressed specimen (FWPSS) ( ext=constant) and c) Fretting Fatigue $(F F)$ (varying $\sum$ ext) tests.

The mechanical properties of 7075 aluminum alloy used are summarized here: Young modulus $E=73000 \mathrm{MPa}, R_{0,2}=460 \mathrm{MPa}, R_{\mathrm{m}}=540 \mathrm{MPa}, \sigma_{\mathrm{D}}=230 \mathrm{MPa}$, Hardness: 160 $\mathrm{VH}, \mathrm{A} \%=11$.

Contact conditions corresponding to a Mixed Fretting Regime have been imposed as cracks initiate earlier than under the Partial Slip Regime. But those conditions are close enough to those encountered under Partial Slip Regime so that negligible wear surface through particle detachment occurs. A spherical aluminum alloy pad of radius $0.3 \mathrm{~m}$ is pressed against the planar tested sample of the same alloy by a constant normal force, $F_{n}=1000 N$. The spherical body is submitted to a reciprocating microdisplacement, $\delta=+/-$ $25 \mu \mathrm{m}$ at a frequency of $5 \mathrm{~Hz}$. This induces an oscillating tangential force, $\mathrm{Q}(\mathrm{t})=+/-500 \mathrm{~N}$, in the contact area. The constant external $\Sigma_{\text {ext }}$ is equal to $230 \mathrm{MPa}$. The ratio between the stick contact zone size, $c$ and the contact zone diameter, $a$ is equal to $c / a=0.9$ (Figure 3(a)). The cracking behavior in both the spherical and the planar pads experiencing respectively FW and FW combined with an external constant load are analyzed in order to identify the contact and external loading influences.

\section{Fretting Crack Morphology}

Multiple cracks initiate in the microsliding zone of the contact area (Figure 3), as revealed by metallographic examination. Crack sites, initiation angles, branching depths, Stage II propagation angles are identical in both FW and FWPSS specimens. The only 
difference is that smaller and less cracks are observed in the FWPS specimen. The crack network is symmetrical with respect to the contact center. Two main cracks develop from this network while most of the other cracks self-arrest. At the contacting surface, cracks propagate along a semi-elliptical trajectory while in the sample depth they progress along two distinct macroscopic directions during respectively macroscopic "Stage I" and "Stage II". The transition between these two periods is revealed by a crack branching along the Stage II propagation direction. Two types of crack are observed during Stage I:

- Type I crack grows initially at a shallow angle to the specimen surface with a propagation direction ranging from $15^{\circ}$ to $35^{\circ}$ to the surface and occurs mainly in the middle of the contact microsliding zone,

- Type II crack grows along a direction approximately perpendicular to the surface with a direction ranging from $75^{\circ}$ to $90^{\circ}$ to the surface and appears near the edge of the contact area in the microsliding zone, inside and/or outside the contact patch.

Furthermore, it was observed that the nearer to the contact center cracks initiate, the shallower to the surface the initial crack growth direction, for both crack types.

Then during Stage II, both types of cracks in both specimens propagate along a direction of approximately $65^{\circ}$ to the surface. The branching depth corresponds roughly to a maximum crack length of $160 \mu \mathrm{m}$.

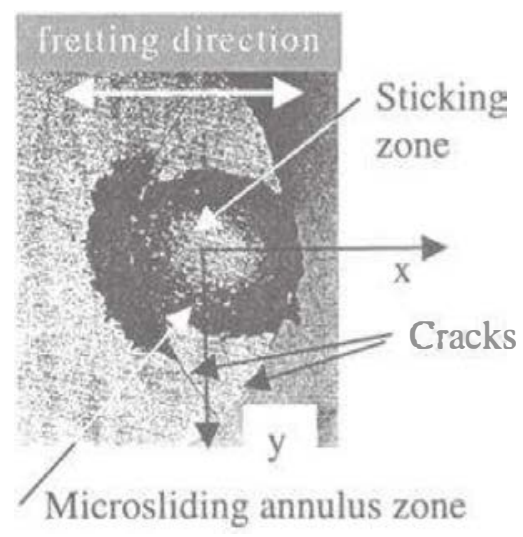

Figure 3(a) - Elliptical cracks at the contacting surface

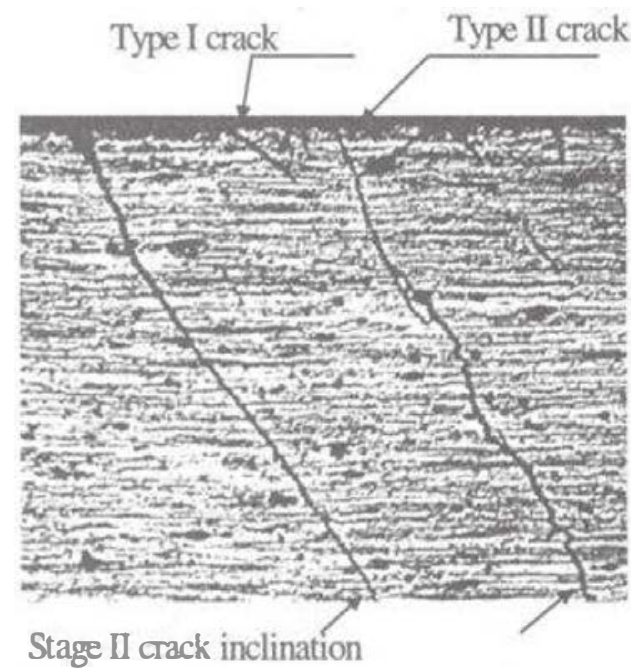

Figure 3(b) - Type I and II cracks in the meridian plane $y=0$

\section{Theoretical Approach}

As a starting point, the cracking behavior is analyzed in the meridian plane $y=0$ and an equivalent two-dimensional cylinder on plane problem is defined. As crack initiation is critically linked to the contact patch dimension [8], the line contact parameters (normal and tangential loads per unit length, cylinder radius) are defined in order that 3D and 2D contact area size, 2a, and maximum hertzian pressure, Po, are identical (Figure 
4). The contact problem is solved as a unilateral contact problem with friction. Coulomb's law is used. An incremental description of the tangential loading is used to account for hysteresis phenomena. Contact area size, sequence of stick and microsliding zones within the contact area, normal and tangential traction distributions are determined.

Crack propagation during Stage I and crack branching mechanisms are investigated on the basis of the continuum stresses induced by the loading. As the stresses in the surface layer change steeply, average stresses are used [9], calculated along planes of length $20 \mu \mathrm{m}$ [2]. These results are briefly recalled before focusing our attention on Stage II propagation.
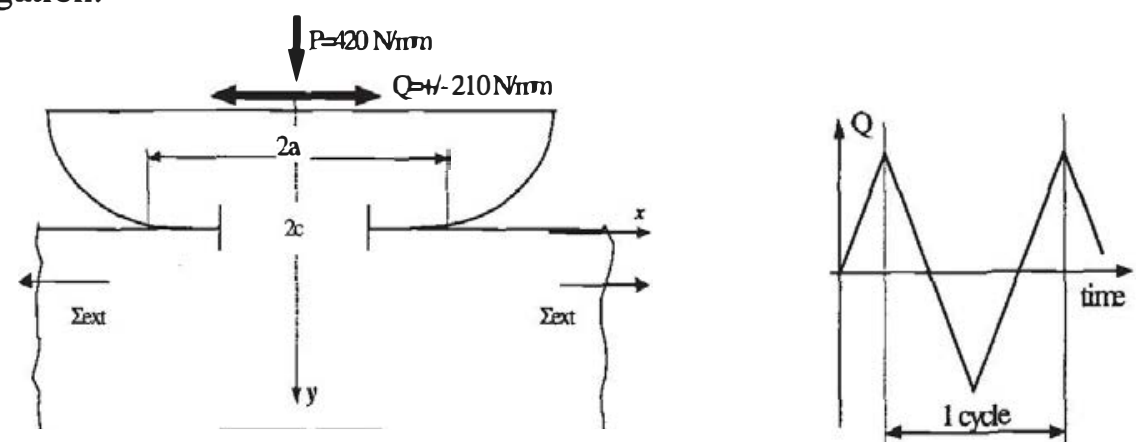

Figure 4 - Cylinder/plane contact model (contact area $2 a=3,57 \mathrm{~mm}$, central stick zone of varying diameter, maximum value $2 c=2,54 \mathrm{~mm}$ ) and tangential variations over a loading cycle.

Stage I [1,2]

The crack initiation mechanisms have been identified theoretically by employing a simple dislocation dipole model and taking into consideration the reverse sliding along two dislocation layers $[9,10]$ and the influence of the distance between these layers [11]. It is shown that cracks may initiate either by an extrusion-intrusion mechanism or a fatigue tensile process. Two parameters, based on the amplitude of the average shear stress $\Delta \tau_{\mathrm{m}}$ and the average tensile stress perpendicular to crack path, $\sigma_{\mathrm{m}}$, have been proposed to predict initiation domains and a single growth direction at each initiation site [1] whereas most of the existing criteria predict initial crack growth direction in the shear mode [9] along two theoretical initial directions.

Type I crack is a shear mode fatigue crack. Its growth occurs macroscopically in the direction $\alpha$ (Figure 5) along which the value of the shear driving force, i.e. the amplitude of the average shear stress, $\Delta \tau_{\mathrm{m}}$ is maximum $\Delta \tau_{\mathrm{m}}=\Delta \tau_{\mathrm{m} \text {,max }}$ and such as the average value $\sigma_{\mathrm{a}}$ of the average tensile stress perpendicular to that direction, $\sigma_{\mathrm{m}}\left(\sigma_{\mathrm{a}=0.5^{*}}\left(\sigma_{\mathrm{m} \text {,max }}+\sigma\right.\right.$ $\mathrm{m}$,min)) is minimum (an absolute value of $40 \mathrm{MPa}$ is here considered for this minimum). Type I crack initiation domain in the contact area satisfies these two conditions. Type I initiation risk is assumed to be the highest where $\sigma_{\mathrm{a}}$ is nil.

Type $I$ crack is a tensile mode fatigue crack. Its nucleation is due to the presence of an initial flaw in the material, either preexisting or formed as a result of dislocation 
movements. The propagation driving force is assumed to be the maximum amplitude of crack opening. The crack extension angle $\alpha$ (Figure 5) is therefore defined by the direction along which the effective amplitude of the average stress normal to crack trajectory $\Delta \sigma_{\mathrm{m}}{ }^{*}$ is maximum, $\Delta \sigma_{\mathrm{m}}{ }^{*}=\Delta \sigma_{\mathrm{m}}{ }^{*}$,max. Further the amplitude of the average shear stress tends to a minimum value along that direction. Type II crack location is therefore near the edge of the contact area, inside or outside of it, where a high level of tensile stress occurs.

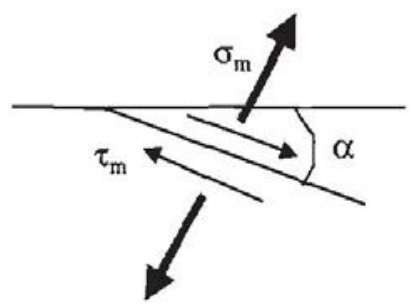

Figure 5 - Average tensile stress $\sigma_{m}$ and shear stress $\tau_{m}$ with respect to $\alpha$ direction

The predicted crack locations and initial growth directions derived from these two criteria are summarized in Figure 6 and are in very good agreement with experimental results.
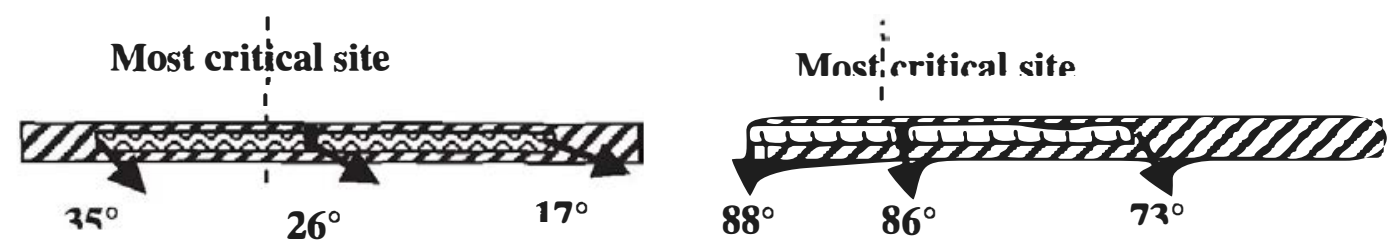

Figure 6 - Theoretical results. Type I crack initiation zone $\approx \widetilde{\text { 柼 }}$ and type II crack initiation zone

Stage I/ Stage II Transition

The conditions leading to transition from Stage I to Stage II are identified [13]. Stage I/Stage II transition corresponds to crack branching along a direction of $65^{\circ}$ for both crack types under FW and FWPSS. Further the branching depths are of the same order of magnitude for both specimens. These observations highlight the contact influence.

For the planar specimen submitted to FW combined with an external constant load, the crack growth mode for both crack types is progressively turned to a mixed $\mathrm{I}+\boldsymbol{I}$ mode within the specimen depth. Thus, the Stage I propagation driving force decreases $\left(\Delta \tau_{\mathrm{m}}\right.$ and $\Delta \sigma_{\mathrm{m}} *$ for type I and II respectively), the crack locking effect increases as $\sigma_{\mathrm{m}}$ perpendicular to crack path becomes gradually more and more compressive and hinders crack slips and opening. Crack self-arrest is therefore unavoidable unless branching occurs. Concomitantly, $\Delta \sigma_{\mathrm{m}}{ }^{*}$ perpendicular to a direction $\beta$ of $65^{\circ}$ increases and along that direction $\Delta \tau_{\mathrm{m}}$ is further minimum. Hence, branching and initial propagation during 
Stage II occurs along a direction $\beta$ along which the amplitude of the crack opening is maximum (and not the opening). Therefore, type I crack branch from a shear mode growth to a tensile mode growth, whereas type II crack branch from a tensile mode growth to a tensile mode growth in order to enhance crack propagation.

For the spherical specimen submitted to FW only, type I and II cracks branch also in the $65^{\circ}$ direction. The decreasing of the initial driving force $\left(\Delta \tau_{\mathrm{m}}\right.$ or $\left.\Delta \sigma_{\mathrm{m}}{ }^{*}\right)$ along the direction $\alpha$ under the contact patch is also combined with crack locking effect raising due to the increase of the compressive value of $\sigma_{\mathrm{m}}$. The $65^{\circ}$ direction is such as along it $\Delta \tau_{\mathrm{m}}$ is minimum and perpendicular to it $\Delta \sigma_{\mathrm{m}} *$ is small, much more small than under FWPSS as the external load is here nil. Therefore, branching occurs in the direction $\beta$ of $65^{\circ}$ that preserves crack opening in order to protect its propagation, whatever the growth mode is.

The contact influence on cracking behavior during Stage I and Stage I/Stage II transition is predominant: crack locations and profiles, branching depths are identical in both specimens. Further the fatigue part of the loading is linked to the contact tangential load.

Stage II

The fretting conditions induce non-proportional mixed mode I+II loading conditions at crack tips. Non-proportional loading is characterized by a varying $\mathrm{K}_{\mathrm{I}} / \mathrm{K}_{\mathrm{II}}$ ratio during a loading cycle while a proportional one is characterized by a constant ratio. As a general rule a crack branches under mixed mode. Classical criteria such as those of Erdogan and Sih (MTS), Tirosh or the S-theory of Sih predict that a crack bifurcates in a direction $\theta_{0}$ where a specific parameter reaches an extreme, respectively the maximum of the tangential stress $\sigma_{\theta \theta}$, the maximum of $\left.\left(\sigma_{\theta \theta}{ }^{2}-\sigma_{\pi}{ }^{2}\right)\right)$ and the minimum of the strain energy density. The bifurcation angle, $\theta_{0}$, is in good agreement with experimental results. These criteria are no longer valid under non-proportional loading. New criteria or extensions of these criteria are therefore required. Hourlier et al. [12] proposed 3 extensions of the MTS criterion, assuming that a crack propagates in a direction corresponding to $\mathrm{k}_{1}{ }^{*}$ max, $\Delta \mathrm{k}_{1} *_{\max }$ or to $(\mathrm{da} / \mathrm{dN})_{\max }$ (Figure 7). Bower [14] proposed also two extensions of the

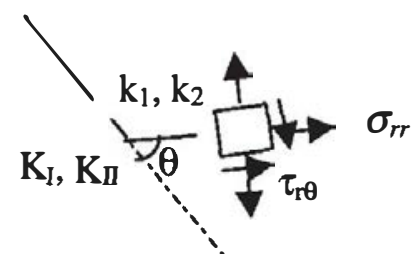

Figure 7 - SIF $K_{I}$ and $K_{I I}$ at initial crack tip, SIF $k_{I}$ and $k_{2}$ at branched crack tip, tangential stress $\sigma_{\theta \theta}$ and shear stress $\tau_{r \theta}$ ahead of crack tip.

MTS criterion. He stated that a crack extends in a direction along which $\mathrm{K}_{\sigma}$ $\left(\mathrm{K}_{\sigma}=\sigma_{\theta \theta} \sqrt{2} 2 \pi \mathrm{r}\right)$ or its amplitude $\Delta \mathrm{K}_{\sigma}$ is maximum over the load cycle, $\mathrm{K}_{\sigma}=\mathrm{K}_{\sigma \max }$ or $\Delta \mathrm{K}_{\sigma}=\Delta \mathrm{K}_{\sigma \max }$. The criterion proposed here is also an extension of the MTS criterion. It is 
assumed that the crack extension angle is linked to the maximum effective amplitude of the tangential stress at crack tip over a load cycle $\Delta \sigma_{\theta \theta}{ }^{*}{ }_{\max }[13]$.

The objective here is to test the applicability of these different approaches. The Stage II propagation is analyzed for the two main cracks situated symmetrically with respect to the contact center (Figure 8). For the cracks situated in the spherical pad, the attention is focused on the conditions leading to self-arrest as they stop very rapidly in the specimen depth while for the cracks situated in the planar specimen the growth angles derived from the different criteria are compared to experimental observations. During Stage II propagation, the cracks extend in the direction of their initial growth at branching leading to a crack extension angle almost equal to zero.

The fretting regime considered inducing a predominant cracking degradation response combined with negligible wear surface through particle detachment allows us to assume that the contacting surfaces are still smooth. Dubourg's fatigue crack model, $[15,16]$ based on the continuous distribution of dislocations coupled with unilateral contact analysis with friction is used. The two main kinked cracks, located in the microsliding zone, where the type I crack initiation risk is important $(x=+/-1.65 \mathrm{~mm})$, are macroscopically modeled by using two straight segments [17] of inclination $\alpha=29^{\circ}$ and $\beta=67^{\circ}$ (Figure 8 ). Seventy-seven discretization points are distributed along each crack, and the loading cycle is described into 81 steps. Stress intensity factors (SIFs) $K_{I}, K_{I I}$ at crack tips and stress fields along crack interfaces are calculated in both specimens. Due to symmetry, the results are presented for the left crack only.

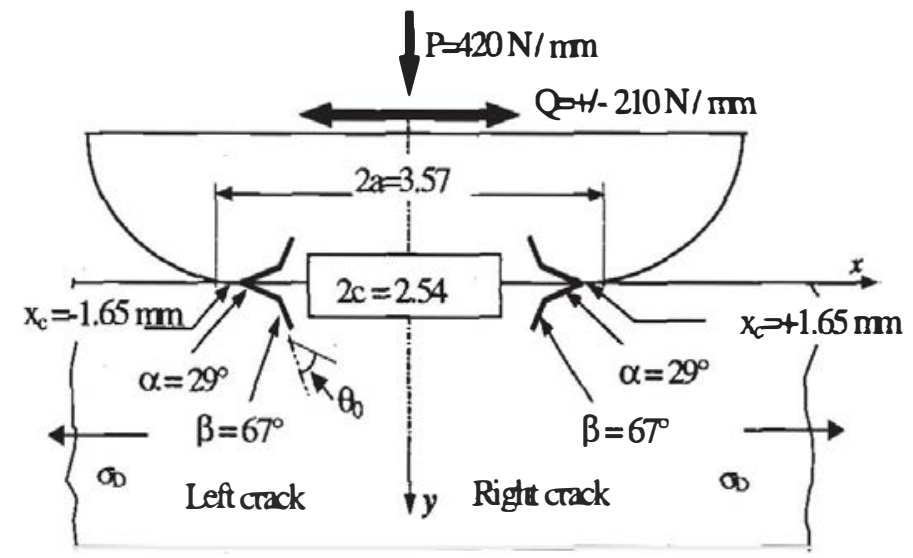

Figure 8 - Loading conditions and main crack locations and profiles.

\section{Cracks Induced by Fretting Wear}

The contact loading induces shear stresses and compressive and tensile subsurface stresses depending on the direction of the surface traction $\mathrm{Q}(\mathrm{t})$ during the loading cycle. The two $500 \mu \mathrm{m}$ long cracks experience mixed mode with a dominant mode II $\left(\Delta \mathrm{K}_{\mathrm{I}} / \Delta \mathrm{K}_{\mathrm{II}}=0.84\right)$ (Figure 9). It may be concluded that crack growth mode is a shear 
mode, although branching was governed by $\Delta \sigma_{\mathrm{m}}{ }^{*}$. It is further shown that maximum $\mathrm{K}_{\mathrm{II}}$ values are obtained when the crack is totally open as slips are not restrained and then hindered by the compressive stresses acting on crack faces. Crack self-arrest is therefore linked to crack closure over the whole loading cycle.

$\mathrm{K}_{\mathrm{I}}$ variations have been computed for crack lengths ranging from 300 to $800 \mu \mathrm{m}$ (Figure 10) under these loading conditions. $800 \mu \mathrm{m}$ is the crack length corresponding to complete closure over a loading cycle. This "critical length" correlates very well with the experimental observations. This length is further linked to the contact patch dimensions and is smaller than a half of the half contact size as shown in Figure 11 where the critical length variations are computed versus the half size of the contact area, the maximum hertzian pressure being constant.

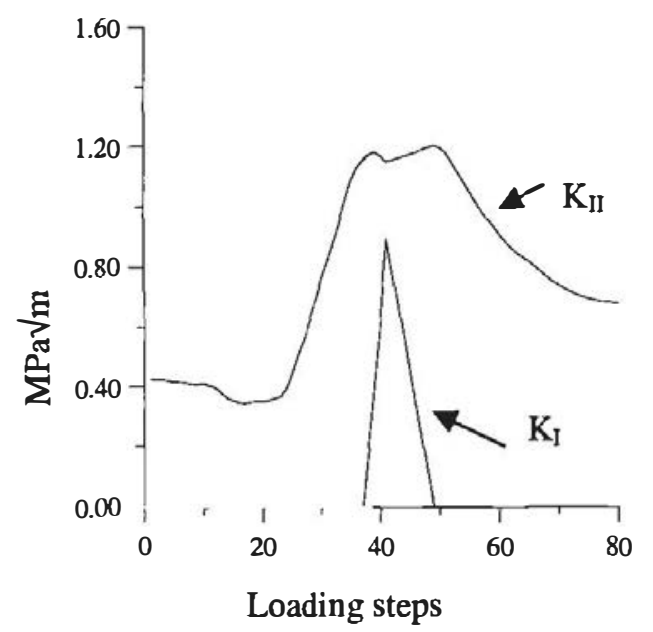

Figure 8 - SIFs at left crack tip over a load cycle. Crack length of $500 \mu \mathrm{m}$.

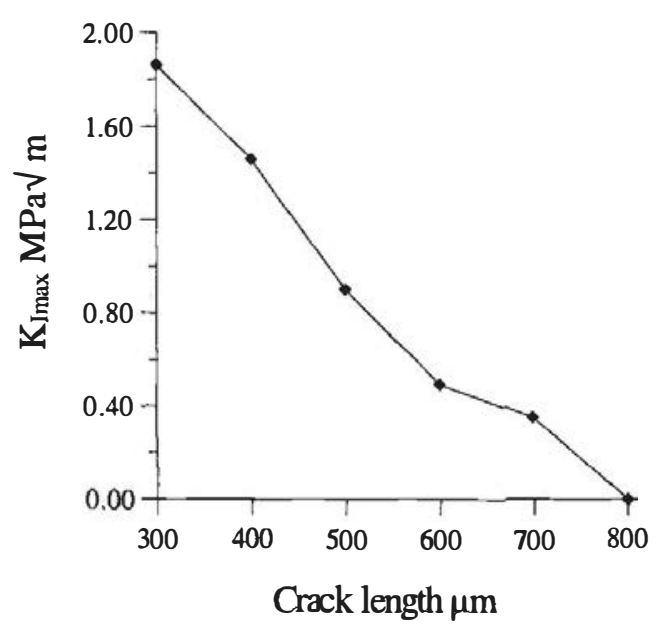

Figure 10 - $K_{\text {lmax }}$ variations over a loading cycle versus crack length. $2 a=3.57 \mathrm{~mm}$, $\mathrm{Po}=150 \mathrm{MPa}$.

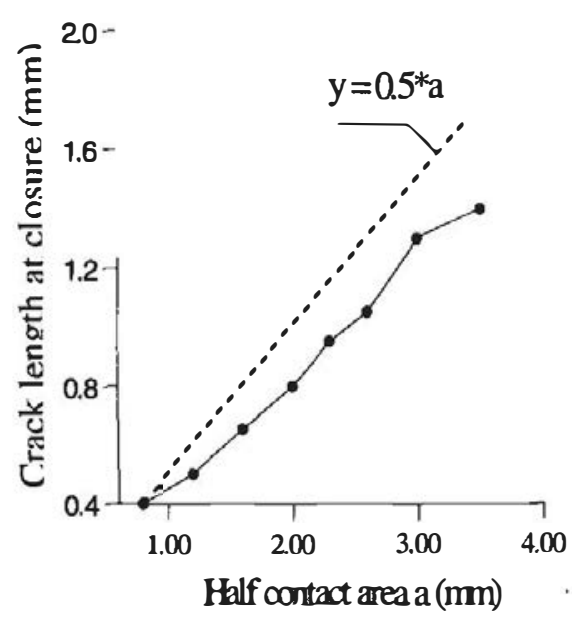

Figure 11 - Crack length at closure versus varying half-contact area $a . P o=150 \mathrm{MPa}$. 


\section{Cracks Induced by Fretting Wear Combined with a Constant External Load}

Crack behavior in the FWPSS is different. The contact loading and the external load act differently but complementary. The contact loading through the tangential loading variation produces the fatigue part of the loading while the constant external load induces average opening and sliding along crack faces that strengthen and extend the influence of the contact. As seen above, the contact influence is limited to the first crack segment corresponding to Stage I propagation. But fatigue crack growth in mode I after branching is only feasible through slips (contact role) acting along the first crack segment that are passed on the open crack tip (external load influence) leading to a varying crack opening.

The crack tips experienced non-proportional mixed mode conditions with a dominant mode I (Figure 12). The ratio $\Delta \mathrm{K}_{\mathrm{I}} / \Delta \mathrm{K}_{\mathrm{II}}$ is equal to 6.35 for $1,2 \mathrm{~mm}$ long crack.

The crack extension angles are determined according to the classical MTS criterion and the different extensions of this MTS criterion cited above. The results are checked at the left crack tip with regards to experimental results.

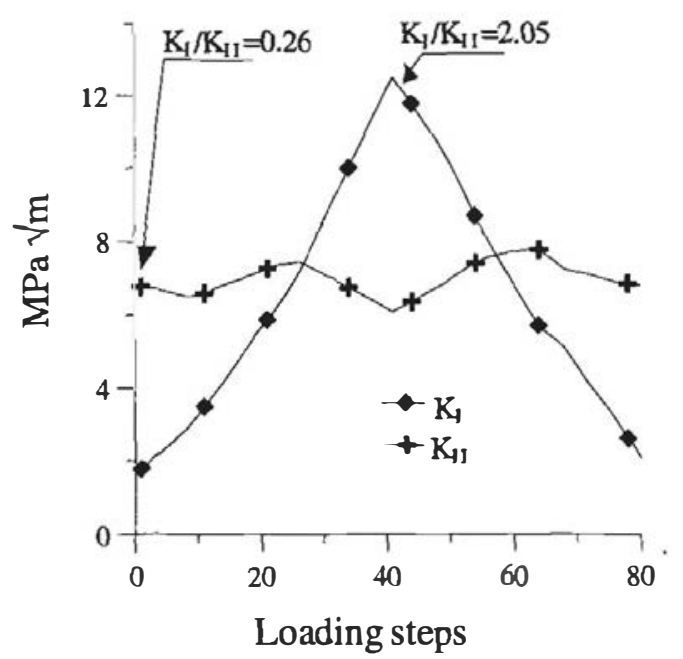

Figure 12 - SIF variations at left crack tip over a load cycle. 1,2 mm crack length.

MTS criterion - This criterion states that a crack extends in the direction normal to the direction of the maximum tangential stress at crack tip $\sigma_{\theta \theta \max }$. The results presented in Figure 13 demonstrate its inapplicability under non-proportional conditions. As $\mathrm{K}_{\mathrm{I}} / \mathrm{K}_{\mathrm{II}}$ varies over the cycle, varying $\theta_{0}$ values are obtained, about $40^{\circ}$ for the right crack and about $-40^{\circ}$ for the left one. Such inclinations do not correlate with the experimental results. 


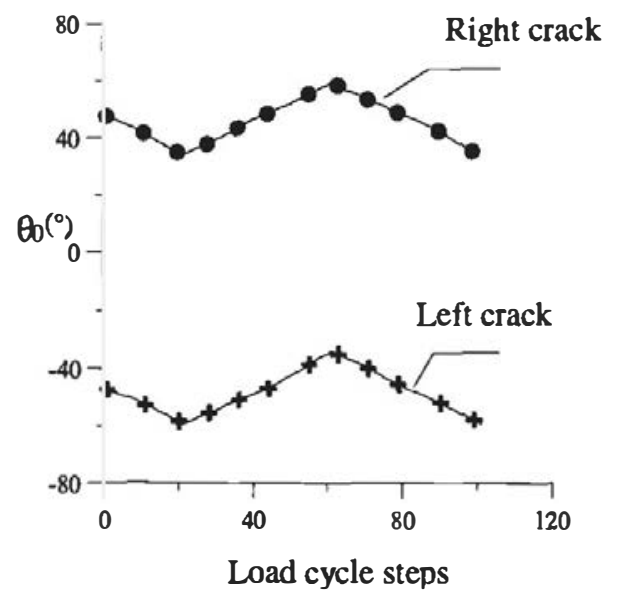

Figure 13 - Crack extension angle $\theta_{0}$ for both cracks according to the MTS criterion.

$k_{l \text { max }}^{*}, \Delta k_{l \text { max }}^{*}$ criteria -3 extensions of the MTS criterion are proposed by Hourlier and Pineau [12]. They assume that a crack propagates either in the direction along which $\mathrm{k}_{1}{ }^{*}\left(\mathrm{k}_{1}{ }^{*}\right.$ and $\mathrm{k}_{2}{ }^{*}$ values are linked to $\mathrm{K}_{\mathrm{I}}$ and $\mathrm{K}_{\mathrm{II}}$ calculated at crack tip before branching [18]) or $\Delta \mathrm{k}_{1}{ }^{*}$ or the crack growth rate $(\mathrm{da} / \mathrm{dN})$ is maximum. The latter criterion is not tested here by lack of experimental data. $\mathrm{k}_{1}{ }^{*} \max , \mathrm{k}_{1}{ }^{*}$ min and $\Delta \mathrm{k}_{1}{ }^{*}$ max variations at left crack tip versus the bifurcation angle $\theta$ defined with respect to the crack direction $\beta$ are presented in Figure 14 over a load cycle.

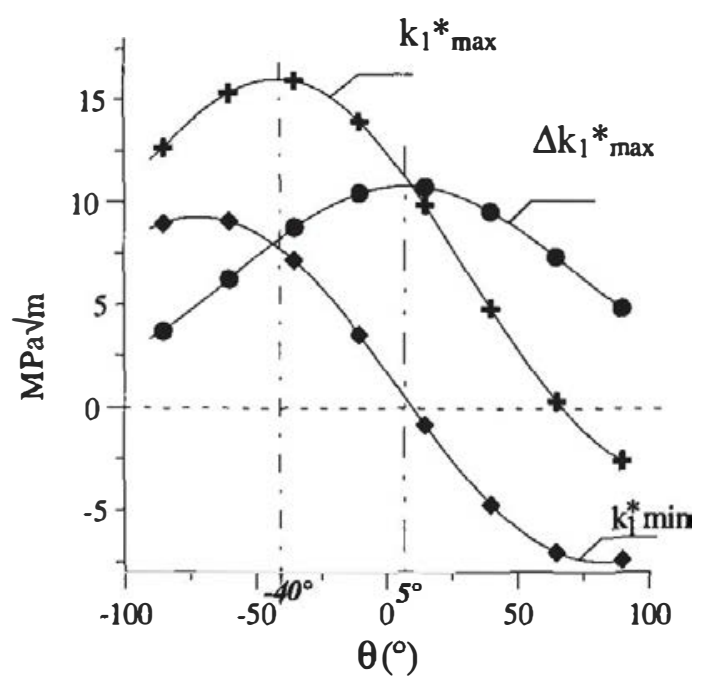

Figure $14-k_{l}{ }^{*}$ max, $k_{l}{ }^{*}$ min and $\Delta k_{l}{ }^{*}$ max variations versus $\theta$ at crack tip over a load cycle.

The angles derived from $\mathrm{k}_{1}{ }^{*}{ }_{\max }$ and $\Delta \mathrm{k}_{1}{ }^{*}$ max criteria are very different and equal to $-40^{\circ}$ and $+5^{\circ}$ respectively. The former approach cannot account for the experimental observations while the latter is in good agreement with the experiments. A crack extends in the direction along which its opening amplitude is maximum and not its opening. 
$K_{\text {omax }}, \Delta K_{\text {omax }}$ criteria - These approaches [14] derive also from the MTS criterion and state that a crack extends in the direction along which $\mathrm{K}_{\sigma}$ respectively $\Delta \mathrm{K}_{\sigma}$ is maximum over a load cycle. $\sigma_{\theta \theta \max }$ and $\Delta \sigma_{\theta \theta_{\max }}$ variations corresponding, respectively, to $\mathrm{K}_{\sigma}$ and $\Delta \mathrm{K}_{\sigma}$ variations versus $\theta$ are determined under the FWPSS conditions over a load cycle and are presented in Figure 15.
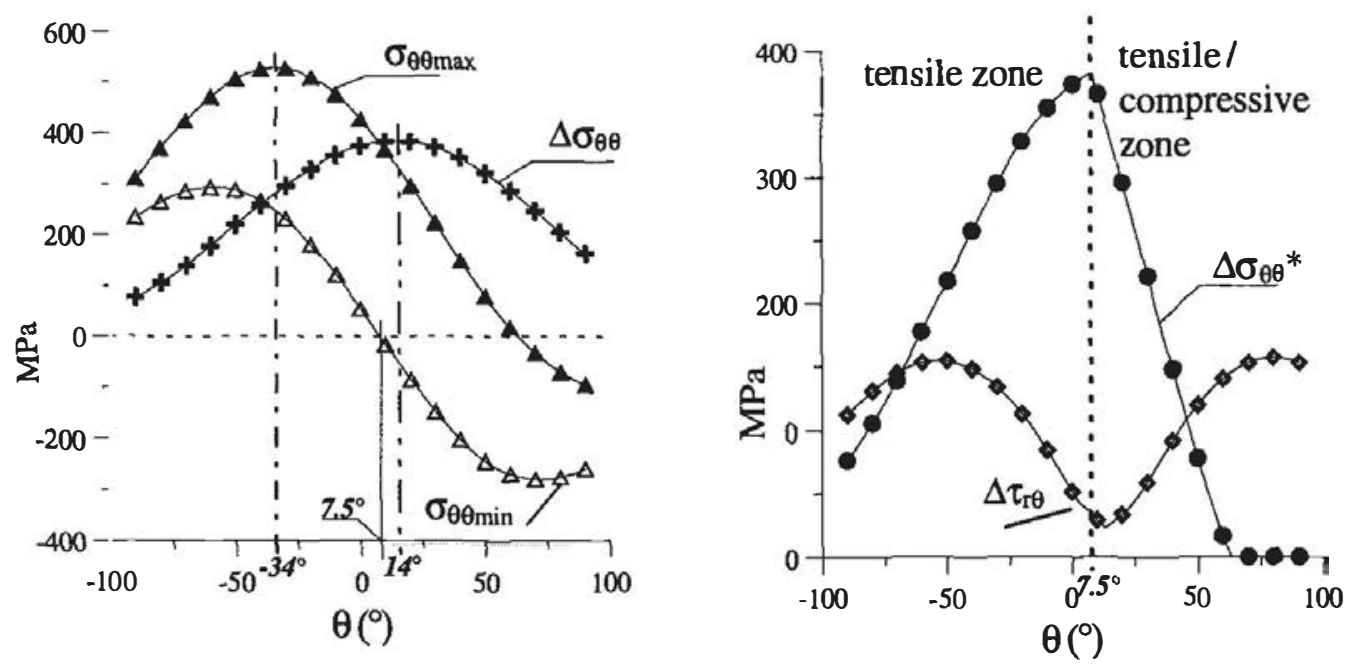

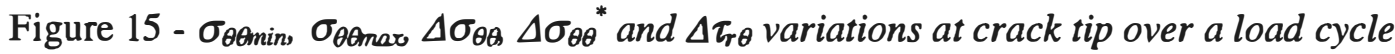
versus the crack extension angle $\theta$.

$\Delta \sigma_{\theta \theta}{ }^{*}$ criterion - This criterion rests on the stress field analysis as performed during the Stage I and Stage I/Stage II transition. The maximum and the minimum tangential stress, the tangential stress amplitude, the effective tangential stress amplitude and the shear stress amplitude respectively $\sigma_{\theta \theta \max }, \sigma_{\theta \theta \min }, \Delta \sigma_{\theta \theta}, \Delta \sigma_{\theta \theta}{ }^{*}$ and $\Delta \tau_{\mathrm{r} \theta}$ are presented in Figure 15 versus $\theta$ over a load cycle for the left crack.

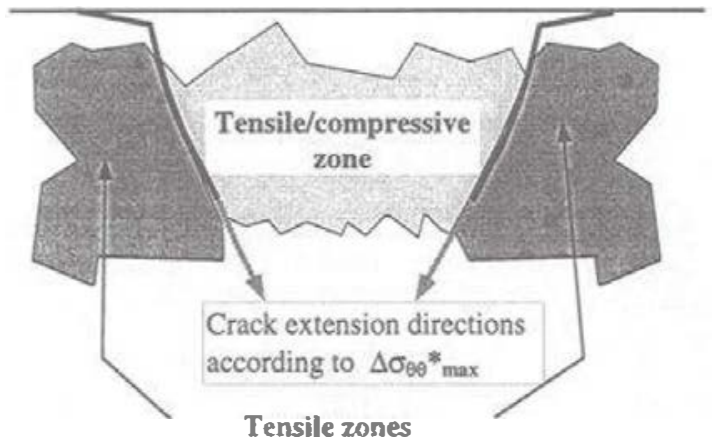

Figure 16 - Tensile and compressive zones surrounding the cracks in the FWPSS.

It appears that $\Delta \sigma_{\theta \theta}{ }^{*}$ gives the best prediction $\theta=+7.5^{\circ}$. Further, the crack path follows a boundary between zones that experience alternatively tensile-compressive and compressive stresses over a load cycle (Figure 16). This extension angle optimizes the crack opening amplitude. This criterion is therefore equivalent to those proposed at Stage I/Stage II transition and based on $\Delta \sigma_{\mathrm{m}}{ }^{*}$, the only difference between these two 
parameters is that the crack response is accounted for in the stress field calculation during Stage II. The mechanisms governing crack growth are therefore identical.

Discussion -The results are summarized in Table 1. The inapplicability of the MTS criterion under non-proportional conditions is clearly established. The crack extension angles derived from the $\mathrm{k}_{1}{ }^{*}$ max, $\mathrm{K}_{\sigma \max }$ approaches can also not account for the experimental results. $\Delta \mathrm{K}_{\sigma \max }$ gives reasonable results but the crack extension angle $\theta_{0}$ is such as the crack tip enters a zone that experiences alternatively compressive and tensile $\sigma_{\theta \theta}$ stresses (Figure 16). Further these compressive stresses will close the crack faces, lead to a decreasing of the opening amplitude over a load cycle and cause a drop in the crack growth speed. The $\Delta \mathrm{k}_{1}{ }^{*}$ max and $\Delta \sigma_{\theta \theta}{ }^{*}$ max criteria give coherent results as they are both based on the concept of the maximum amplitude of crack opening.

Table 1 - Crack extension angles $\theta_{0}$ derived from the different criteria

\begin{tabular}{ccc} 
Criterion & $\theta_{0}$ for left crack & $\theta_{0}$ for right crack \\
\hline $\mathrm{K}_{1}^{*}{ }_{\max }^{\prime}$ & $-40^{\circ}$ & $+40^{\circ}$ \\
$\Delta \mathrm{k}_{1 \text { max }}^{*}$ & $+5^{\circ}$ & $-5^{\circ}$ \\
$\sigma_{\theta \theta \max } \Leftrightarrow \mathrm{K}_{\sigma \max }$ & $-34^{\circ}$ & $+34^{\circ}$ \\
$\Delta \sigma_{\theta \theta \max } \Leftrightarrow \Delta \mathrm{K}_{\sigma \max }$ & $+14^{\circ}$ & $-14^{\circ}$ \\
$\Delta \sigma_{\theta \theta \max }$ & $+7.5^{\circ}$ & $-7.5^{\circ}$
\end{tabular}

\section{Conclusion}

The objectives of this work were to improve our understanding at a macroscopic scale of crack initiation and propagation mechanisms under fretting conditions. A combined experimental and theoretical approach has been developed. Thanks to the fretting map concepts, experiments have been performed under running conditions corresponding, to Mixed Fretting Regime and Partial Slip Regime that led to a predominant cracking degradation response.

Reproducible data on crack location, crack inclination within specimen depth, crack branching depth have been obtained in Fretting Wear specimens and Fretting Wear PreStressed Specimens. Further the crack network is identical in both specimens with respect to crack sites and initial growth directions. Macroscopic Stage I and Stage II periods have been defined, corresponding to two different macroscopic crack growth directions. During Stage I, two different crack types have been observed. Type I crack is 
a shear mode fatigue crack while type II crack is a tensile mode fatigue crack. Crack branching occurs at the Stage I/Stage II transition and then both crack types, in both specimens, propagate in a direction of $65^{\circ}$ with respect to the specimen surface, but the cracks induced by Fretting Wear (the spherical specimen) self-arrest rapidly.

Theoretically, crack initiation and propagation during Stage I, Stage I/Stage II transition and Stage II have been investigated. A new approach has been proposed following $[9,11]$ to predict the crack location and the crack growth initial angle during Stage I and contrary to general initiation criteria. This model has enabled us to predict a single initiation plane for shear mode fatigue crack [1]. The conditions governing the crack branching have also been identified. It has been shown that the contact loading has a predominant influence during this stage.

A new criterion has been proposed to predict the crack extension angle during Stage II. As cracks experience non-proportional mixed mode fatigue under fretting loading, the classical criteria proposed for the crack path determination are no longer valid. The MTS criterion and different extensions derived from this criterion proposed by Houlier and

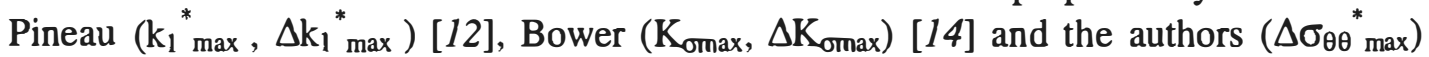
have been tested and checked with regards to the experimental results. It is shown that $\Delta \sigma_{\theta \theta}{ }^{*}$ max and $\Delta \mathrm{k}_{1}{ }^{*}$ max can account for the experimental results. They are further coherent as they both state that a crack propagates in a direction along which its opening amplitude is maximum. It has been further demonstrated that this mode I propagation is feasible through the contact loading and the constant external loading combination. The external loading induces a constant opening at crack tip. Without it, cracks self-arrest (FW specimen) and the corresponding crack length is linked to the contact patch dimension. In the FWPSS, varying opening at crack tip is indeed due to the slips acting along the initial crack direction that are passed on the open crack tip.

\section{References}

[1] Reybet Degat, P., Lamacq, V., Dubourg, M. C., Zhou, Z. R., Vincent, L., "Experimental and Theoretical Approach to Fretting Crack Nucleation on Prestressed Aluminum Alloy", ECF 11, Mechanisms and Mechanics of Damage and Failure, 1996, pp 1443-1445.

[2] Lamacq, V., Dubourg, M. C., Vincent, L., "A Theoretical Model for the Prediction of Fretting Fatigue Crack Initial Growth Angles and Sites", Tribology International, Vol. 30, $\mathrm{n}^{\circ}$ 6, 1997, pp. 391-400.

[3] Vincent, L., Berthier, Y., Dubourg, M. C. and Godet, M., "Mechanics and Materials in Fretting", Wear, Vol. 153, 1992, pp. 135-148.

[4] Vincent L., Berthier Y. and Godet M., "Testing Methods in Fretting Fatigue: A Critical Appraisal”, ASTM-STP 1159, 1992, pp. 33-48 
[5] Fouvry, S., Kapsa, P., Vincent, L., “Quantification of Fretting Damage”, Wear 200, 1996, pp. 186-205.

[6] Reybet Degat, P., Zhou, Z. R., Vincent, L., "Fretting Behavior on Pre-stressed Aluminum Alloy Specimen”, Tribology International, Vol. 30, n³, 1996, pp 711720.

[7] Zhou, Z., R., Vincent, L., “Mixed Fretting Regime”, Wear 181-183, 1995, pp. 531536.

[8] Nowells, D., Hills, D.A., "Crack Initiation Criteria in Fretting Fatigue”, Wear, Vol. 135,1990 , pp. 329-343.

[9] Yamashita, N. and Mura, T., "Contact Fatigue Crack Initiation under Repeated Oblique Force”, Wear, 91, 1983, pp. 235-250.

[10] Tanaka, N., Mura, T., “A Dislocation Model For Fatigue Crack Initiation”, Journal of Applied Mechanics, 47, 1981, pp. 111-113.

[11] Mura, T., Nakasone, Y., "A Theory of Fatigue Crack Initiation in Solids", Journal of Applied Mechanics, Vol. 57, 1990, pp 1-6.

[12] Hourlier, F., Pineau, A., "Fatigue Crack Path Behavior under Complex Mode Loading", in Advances in Fracture Research, Proceedings $5^{\text {th }}$ International Conference on Fracture, Pergamon, Oxford, Vol. 4, 1981, pp. 1841-1849.

[13] Lamacq, V., “ Amorçage et Propagation de Fissures de Fatigue sous Conditions de Fretting”, Thèse: Doctorat, INSA, 1997, 251 p.

[14] Bower, A., F., "The influence of Crack Face Friction and Trapped Fluid on Surface Initiated Rolling Contact Fatigue Cracks", Journal of Tribology, Transaction of the ASME, 110, 1988, pp. 704-711.

[15] Dubourg, M. C., Villechaise, B., "Analysis of Multiple Cracks - Part I: Theory", ASME, Journal of Tribology, Vol. 114, 1992, pp 455-461.

[16] Dubourg, M. C., Godet, M., Villechaise, B., "Analysis of Multiple Cracks - Part II: Results”, ASME, Journal of Tribology, Vol. 114, 1992, pp. 462-468.

[17] Dubourg, M.C., Villechaise, B., "Stress Intensity Factors in a Bent Crack: a Model", European Journal of Mechanics, A/Solids, 11, n², 1992, pp. 169-179.

[18] Amestoy, M., Bui H. D., Dang Van K., "Déviation Infinitésimale d'une Fissure dans une Direction Arbitraire", Compte Rendu Académie des Sciences Paris, t. 289, Série B, 1979, pp. 99-102 